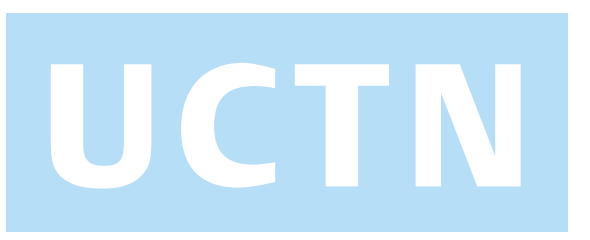

Endoscopic variceal ligation (EVL) is now considered to be demonstrably superior to endoscopic variceal sclerotherapy (EVS), particularly with regard to procedure-related morbidity [1]. The use of multiple-band ligators has made ligation technically easier and faster, but the long-term results of EVL are less encouraging, due to early variceal recurrence. This is particularly the case in patients with unresectable hepatocellular carcinoma and esophageal bleeding, who experience extremely high rates of recurrent bleeding and mortality [2].

A 51-year-old woman with Child-Pugh class A cirrhosis and chronic hepatitis B
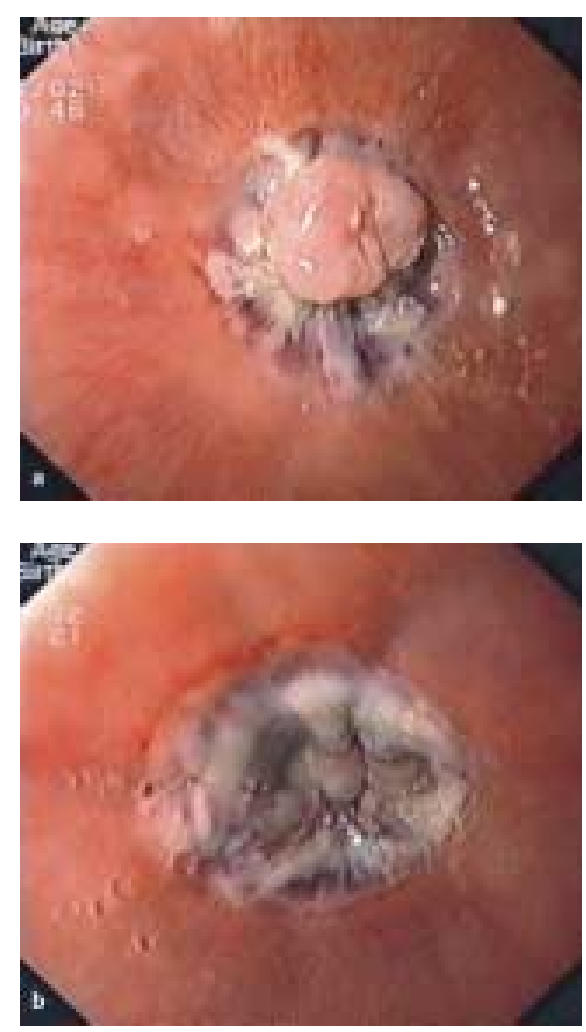

Figure 1 a Endoscopic view of the ligation band which included the whole circumference of the esophagus. The position of the lumen of the esophagus is represented by a slight depression in the center of the ligated esophageal mucosa. $\mathbf{b}$ The band was pushed down the esophagus with the endoscope. Circumferential necrotic mucosa was noted on withdrawal and there was no sign of active bleeding.

\title{
Aphagia Caused by Accidental Banding of the Esophageal Circumference
}

presented in December 2001 with hematemesis and melena. Active bleeding from large esophageal varices was observed which stopped after the application of the first elastic band over the bleeding site. Color Doppler transabdominal ultrasound and conventional computed tomography revealed a large diffuse hepatocellular carcinoma involving the right hepatic lobe, a large portal vein thrombosis ( $20 \mathrm{~mm}$ ), extensive collaterals in the hepatic hilum, and gallbladder varices, suggestive of a malignant cavernomatous transformation of the portal vein. Eradication of the esophageal varices was achieved in four EVL sessions, using the Saeed six-shooter Multi-Band Ligator (Wilson Cook, Winston-Salem, North Carolina, USA).

Immediately after the last EVL session, however, the patient developed complete esophageal obstruction complaining of inability to swallow either food or liquids (aphagia). This persisted for 48 hours, despite the administration of prokinetics. A subsequent examination showed that the last band had ligated the whole circumference of the esophagus (Figure $\mathbf{1} \mathbf{a}$ ). The band was pushed down with the endoscope and a circumferential area of necrotic mucosa was noted on withdrawal (Figure $\mathbf{1}$ b). Immediately after this proce-

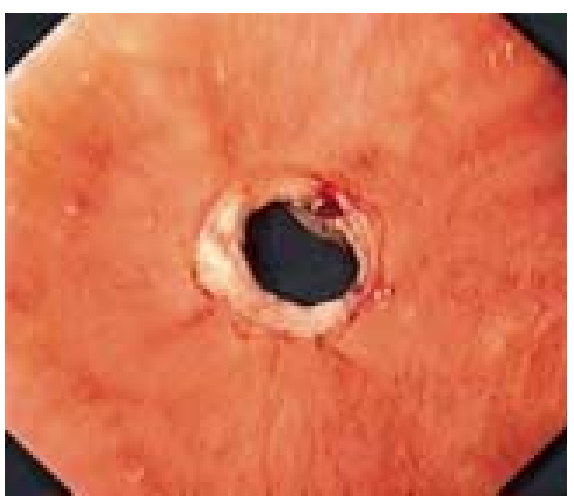

Figure 2 Circumferential stricture noted on follow-up endoscopic examination 10 days after band ligation and subsequent endoscopic relief of the obstruction. Note the small tear at the 1 o'clock position after the stricture was passed by the endoscope. dure the patient was able to swallow liquids, although this was accompanied by a sensation of retrosternal discomfort. At a follow-up endoscopy after 10 days, a circumferential stricture with a diameter of approximately $10 \mathrm{~mm}$ was observed. After the stricture was gently passed with the endoscope, a small tear with minimal bleeding was noted (Figure 2). The patient is well after 1 month, with minimal dysphagia for solids.

To the best of our knowledge, this is the first case of accidental ligation of the whole circumference of the esophagus with complete esophageal obstruction. Accidental ligation of the arytenoid and accidental banding of the major papilla during ligation of duodenal varices have been reported $[3,4]$. However, these complications are rare and the main advantage of EVL is still considered to be the low rate of treatment-induced complications when compared with EVS [5]. Interestingly, in our patient, the band was tight enough to hold the esophageal wall mucosa for 48 hours with complete esophageal obstruction, despite esophageal peristalsis and the administration of prokinetics.

\section{A. Săftoiu, T. Ciurea}

Department of Internal Medicine, Division of Gastroenterology, Faculty of Medicine, University of Medicine and Pharmacy, Craiova, Romania

\section{References}

${ }^{1}$ Seewald S, Seitz U, Yang AM, Soehendra N. Variceal bleeding and portal hypertension: still a therapeutic challenge? Endoscopy 2001; 33: 126 - 139

${ }^{2}$ Chen WC, Hou MC, Lin HG et al. Feasibility and potential benefit of maintenance endoscopic variceal ligation in patients with unresectable hepatocellular carcinoma and acute esophageal variceal hemorrhage: a controlled trial. Gastrointest Endosc 2001; 54: 18 - 23 
${ }^{3}$ Akdogan M, Parlak E, Ulker A, Dagli S. Accidental arytenoid banding: an unusual complication of single-shot ligation therapy. Endoscopy 2001; 33: 193

${ }^{4}$ Silberzweig JE, Atillasoy EO, Sheiner PA, Mitty HA. Biliary obstruction caused by endoscopic band ligation of a duodenal varix. Am J Gastroenterol 1997; 92: 1060-1062
${ }^{5}$ Kitano S, Baatar D. Endoscopic treatment for esophageal varices: will there be a place for sclerotherapy during the forthcoming era of ligation? Gastrointest Endosc 2000; 52: 226-232
Corresponding Author

A. Săftoiu, M.D.

Department of Internal Medicine Division of Gastroenterology Faculty of Medicine University of Medicine and Pharmacy Str. Horia nr. 11 Craiova, Dolj, RO-1100 Romania

Fax: $\quad$ + 40-51-134596

E-mail: adry@umfcv.ro

\section{Highlights from Forthcoming Issues}

\section{State-of-the-Art-Reviews}

Premedication and Monitoring

Reflux and Barrett's Esophagus

Ulcers and Gastritis

Non-Variceal Upper GI Bleeding

Variceal Bleeding and Portal Hypertension

Diagnosis of Upper Gl Tumors

Treatment of Upper GI Tumors

\section{Original Articles}

Young Patients and Endoscopy for Earlier Cancer Diagnosis

Open Access Endoscopy: Are Age Based Guidelines Justified?

Minilaparoscopy and the Diagnosis of Liver Cirrhosis

\section{Editorials}

Is Age a Good Discriminator for Performing Gastroscopy?

Minilaparoscopy for Early Diagnosis of Cirrhosis: Endoscopy versus Histopathology 